\title{
Genetic Variability, Heritability and Genetic Advance in Bitter Gourd: A Review
}

\author{
Priyambada Pradhan ${ }^{1 *}$, Shyama Sourabh ${ }^{2}$ and Soumya Sakti Dash ${ }^{3}$ \\ ${ }^{1}$ Department of Horticulture, School of Agriculture, GIET University, Gunupur, Odisha, India \\ ${ }^{2}$ Department of Vegetable Science, ${ }^{3}$ Dept. of Extension education, College of Agriculture, \\ OUAT, Bhubaneswar, Odisha, India \\ *Corresponding author
}

A B S T R A C T

\begin{tabular}{l} 
K e y w o r d s \\
Bitter gourd, \\
Genetic variability, \\
Heritability, \\
Genetic advance \\
Article Info \\
$\begin{array}{l}\text { Accepted: } \\
\text { 22 June } 2020 \\
\text { Available Online: } \\
\text { 10 July } 2020\end{array}$ \\
\hline
\end{tabular}

\section{Introduction}

Bitter gourd (Momordica charantia L.) is an important vegetable crop belongs to family Cucurbitaceae. It is locally known as Bitter Melon, Karela, Maiden apple and Balsam pear etc. Being an important contributor of vitamins and minerals particularly iron, phosphorus and ascorbic acid, bitter gourd ranks first among other cucurbits (Singh et al., 2012). The fruit contains two alkaloids viz., momordicin and cucurbitacin. A hypoglycemic principle called "charantin" has been isolated which is used for the treatment of diabetes (Raman and Lau, 1996). Due to increasing awareness about the nutritional and anti-diabetic value of bitter gourd, its demand has been increased both in domestic and international market. It has been identified as one of the potent vegetable for export by Agricultural Processed Food Products and Export Development Authority (APEDA) next to onion and okra in India. For any planned breeding programme aimed to improve yield potentials of crops, it is necessary to obtain adequate information on the magnitude of genetic variability, heritability and genetic advance present in the population (Singh et al., 2017). 


\section{Genetic Variability}

The selection of superior genotypes is the most important aspect of any crop improvement programme and the effectiveness of the selection primarily depends on the existence of genetic variability within or between the populations subjected for selection. Therefore, any successful breeding programme requires the study of genetic variability. Knowledge of the nature and magnitude of genetic variation in terms of quantitative plant growth characteristics coupled with yield and its components is essential for improvement of a crop. The variability in the population can be estimated by various parameters like mean, range, genotypic and phenotypic coefficient of variations i.e. GCV and PCV together with heritability and genetic advance (GA).

The variability ascertained for any character is not solely because of variations in genetic constitutions of the population, rather conjointly due to the environmental conditions. The evident quantitative attribute is just the phenotype which may be simply assessed for selection. Hence, phenotypic selection is insufficient since it is the sum total effect of genotype, environment and interaction of genotype and environment. However, phenotypic selection also creates difficulty to establish whether variability is heritable or non-heritable (environmental). This needs the partitioning of total variations or phenotypic variations into two groups such as heritable and non-heritable.

In bitter gourd wide range of variability for a number of characters has been observed by several workers in India (Agasimani et al., 2008; Yadav et al., 2008; Rajput et al., 2012; Singh et al., 2012; Nandakumar et al., 2014; Kumari et al., 2015; Gupta et al., 2016 and Talukdar et al., 2018). Ram et al., (2006) and Agasimani et al., (2008) reported maximum coefficient of variations for characters like days to male flower emergence, seed weight fruit $^{-1}$, yield plant ${ }^{-1}$, fruit weight and fruit length in bitter gourd. While evaluating 17 genotypes of bitter gourd, Khan et al., (2015) observed highest variation in vine length. Talukdar et al., (2018) showed that there was significantly higher amount of variations among the genotypes for all the characters studied viz., vine length, branches $v^{2} \mathrm{e}^{-1}$, nodes vine ${ }^{-1}$, days to $1^{\text {st }}$ male flowering, days to $1^{\text {st }}$ female flowering, fruit length, fruit diameter, fruit weight, fruits plant ${ }^{-1}$ and fruit yield plant ${ }^{-1}$ but on the contrary, for these characters the variation due to replication was found to be non-significant. Similar results were also revealed by Singh et al., (2017) except for total soluble solids (TSS).

$\mathrm{PCV}$ is the sum total of GCV and environment coefficient of variation (ECV). The closeness between PCV and GCV simply indicate the stability of traits in different environment. For effective selection of any traits, the PCV and GCV value should have minimum difference. In bitter gourd, several studies indicated higher PCV values than corresponding GCV values (Bhave et al., 2003; Narayan et al., 2006; Rajput et al., 2012; Singh et al., 2012 and Gupta et al., 2016) indicating influence of environmental factors in expression of these traits. In $\mathrm{F}_{2}$ and $\mathrm{F}_{3}$ segregating generations of bitter gourd, Rajput et al., (2012) reported high GCV and PCV for primary branches vine ${ }^{-1}$, sex ratio, fruits vine ${ }^{-1}$, female flowers vine $e^{-1}$, fruit yield vine $^{-1}$, average yield $v_{\text {ine }}{ }^{-1}$, fruit flesh thickness and average weight of fruit. They also suggested that there was presence of greater amount of variability for yield attributes and this could be further improved by simple selection method. Similarly, for $\mathrm{F}_{3}$ and $\mathrm{F}_{4}$ generations of bitter gourd, the GCV and PCV were higher for primary branches vine $^{-1}$, average yield vine ${ }^{-1}$, average weight of fruit and fruit yield (tha ${ }^{-1}$ ) (Nandakumar, 
2014). Similar findings were reported by Gupta et al., (2016) for marketable fruit yield ha $^{-1}$ along with branches plant ${ }^{-1}$ and total fruit yield plant ${ }^{-1}$ while studying 26 genotypes of bitter gourd. Pathak et al., (2014) estimated the same for the characters like fruits plant ${ }^{-1}$, fruit weight and fruit length. Higher magnitude of GCV and PCV was recorded for fruit yield vine ${ }^{-1}$ (Singh et al., 2015 and Singh et al., 2017), fruits vine ${ }^{-1}$ (Singh et al., 2015), fruit girth and fruit length (Gowda, 2017). A narrow difference was observed between the values of PCV and GCV indicating the least influence of environment in the expression of the traits (Singh et al., 2014 and Rani et al., 2015). Singh et al., (2014) and Iqbal et al., (2016) observed that majority of variations in traits was due to genetics through the differences between GCV and PCV.

Highest estimates of GCV were obtained for yield vine ${ }^{-1}$ (Singh et al., 2014), average fruit weight and fruits vine ${ }^{-1}$ (Dey et al., 2005; Khan et al., 2015; Rani et al., 2015 and Talukdar et al., 2018). Along with these traits, characters like branches vine ${ }^{-1}$ (Khan et al., 2015) and fruit length (Talukdar et al., 2018) also showed highest GCV values. On the other hand, Singh et al., (2012) assessed high PCV for yield vine ${ }^{-1}$, number of fruits vine ${ }^{-1}$ and fruit diameter. Similarly, maximum PCV was observed for branches plant ${ }^{-1}$ (Dalamu and Behera, 2013), yield vine ${ }^{-1}$, fruit weight, seed weight fruit ${ }^{-1}$, length of fruit, number of seeds fruit ${ }^{-1}$, internodal distance vine $^{-1}$ (Yadagiri et al., 2016) and total carotenoid content and fruit yield (Sindhu et al., 2017).

Characters like vine length, number of primary branches vine ${ }^{-1}$, fruit length, fruit weight and fruit diameter showed moderate GCV and PCV in bitter gourd (Singh et al., 2017). Similar results had also been reported by Kutty and Dharmatti (2004) in bitter gourd.
Lower estimates of GCV and PCV were observed for number of nodes bearing the $1^{\text {st }}$ male flower, percent of fruit setting, days to $1^{\text {st }}$ fruit harvest, number of fruits vine ${ }^{-1}$, ascorbic acid, total soluble solids (Singh et al., 2017 and Kutty and Dharmatti, 2004) and days to $1^{\text {st }}$ male flower and female flower (Khan et al., 2015; Singh et al., 2017 and Talukdar et al., 2018).

\section{Heritability}

Heritability is the heritable component which can be passed from generation to generation whereas; GA is the expected percent of gain of a particular character in the next generation. So, to get the desirable characters in bitter gourd, a number of workers has been reported high, medium or low heritability $\left(\mathrm{h}^{2}\right)$ coupled with GA (high, medium or low) as percent of mean. Higher values of heritability was observed for characters like average fruit length, fruits plant ${ }^{-1}$, fruit yield vine ${ }^{-1}$, vine length and branches vine ${ }^{-1}$ (Singh et al., 2012; Gupta et al., 2013; Rani et al., 2015; Singh et al., 2017 and Talukdar et al., 2018). Addition to these characters, Rani et al., (2015) noticed the same for days to $1^{\text {st }}$ female flower and pulp thickness. Similarly, moderate heritability was observed for fruits vine ${ }^{-1}$, fruit weight, fruit girth, seeds fruit $^{-1}$, days to $1^{\text {st }}$ male flower and days to $1^{\text {st }}$ female flower (Rani et al., 2013); fruit length, number of node bearing $1^{\text {st }}$ male and female flower, internodal length, days to $1^{\text {st }}$ male flower appearance and sex ratio (Rani et al., 2015); days to $1^{\text {st }}$ seed germination, germination rate (Singh et al., 2017) and fruit weight (Singh et al., 2012 and Rani et al., 2013), which revealed that the additive gene effects coupled with high environment impact on these traits. In contradiction to these findings, Rani et al., (2013) observed lower values of heritability for fruit length, plant height, laterals vine ${ }^{-1}$, number of node bearing $1^{\text {st }}$ male and female flower, sex ratio and pulp thickness. Similar 
values were obtained for days to $1^{\text {st }}$ picking (Gupta et al., 2013) and number of seeds fruit ${ }^{1}$ (Rani et al., 2015).

\section{Heritability and genetic advance}

High heritability coupled with high GA was noticed for yield vine ${ }^{-1}$ (Rajput et al., 1996; Kutty and Dharmatti, 2004; Devmore et al., 2010; Rani et al., 2015 and Yadagiri et al., 2016), number of fruits vine ${ }^{-1}$ (Narayan et al., 2006; Pathak et al., 2014; Rani et al., 2015 and Sidhu et al., 2017), average fruit weight (Pathak et al., 2014; Singh et al., 2014; Rani et al., 2015; Yadagiri et al., 2016 and Gowda, 2017), fruit length (Narayan et al., 2006; Pathak et al., 2014; Singh et al., 2014; Rani et al., 2015; Iqbal et al., 2016 and Yadagiri et al., 2016), vine length (Rani et al., 2015 and Yadagiri et al., 2016), number of node bearing $1^{\text {st }}$ male and female flower (Sidhu et al., 2017), pH, ${ }^{\circ}$ Brix (Iqbal et al., 2016), total marketable fruit yield (Gupta et al., 2016), fruit size (Gupta et al., 2013 and Gupta et al., 2016), plant height (Singh et al., 2006), vitamin C (Iqbal et al., 2016 and Sidhu et al., 2017) and seeds fruit ${ }^{-1}$ (Singh et al., 2014; Gupta et al., 2016 and Yadagiri et al., 2016). On the other hand, Pathak et al., (2014) reported high heritability with lower GA for days to $1^{\text {st }}$ male flower anthesis, days to $1^{\text {st }}$ female flower anthesis and days to marketable maturity from anthesis. In addition to these characters, Singh et al., (2006), Islam et al., (2009), Singh et al., (2014) and Kundu et al., (2016) observed the same for branches vine ${ }^{-1}$, fruit diameter, fruit length, fruits plant ${ }^{-1}$, seeds fruit $^{-1}$ and yield fruit ${ }^{-1}$. High heritability with moderate GA was observed for fruit length (Singh et al., 2006).

High GCV along with high heritability and greater GA was noticed for fruits plant ${ }^{-1}$, fruit weight (Mangal et al., 1983; Devmore et al., 2010; Dalamu and Behera, 2013 and Rani et al., 2015), fruit yield $v^{-1} e^{-1}$, fruit length, branches vine $^{-1}$ (Mangal et al., 1983; Narayan et al., 2006 and Rani et al., 2015), fruit diameter (Narayan et al., 2006), number of nodes vine ${ }^{-1}$ and days to $1^{\text {st }}$ fruit harvest (Rajput et al., 1996; Kutty and Dharmatti, 2004 and Devmore et al., 2010) which would be of great use for indirect selection for improvement in yield plant ${ }^{-1}$ in bitter gourd. On the other hand, traits like number of lobbings leaf ${ }^{-1}$, number of days to $1^{\text {st }}$ female flower showed low heritability along with low GA and low GCV (Mangal et al., 1983).

\section{References}

Agasimani, SC, Salimath PM, Dharmatti and Laxuman. 2008. Stability for fruit yield and its components in bittergourd (Momordica charantia L.), Vegetable Science, 35(2): 140-143.

Choudhary, D, Srivastava DP, Ghosh AK and Seetharaman. 1973. Genetic variability and correlation for yield components in rice, Indian journal of Agricultural Sciences, 43: 181-184.

Dey, SS, Behera TK, Munshi AD and Sirohi PS. 2005. Studies on genetic divergence in bitter gourd (Momordica charantia L.), Indian Journal of Horticulture, 64(1): 53-57.

Devmore JP, Dhonukshe BL, Thaware BL, Jadhav VW amd Thaprat TN. 2010. Genetic variability and heritability studies in bitter gourd (Momordica charantia L.),Journal of Maharashtra Agricultural University, 35(1):163-165.

Gupta N, Bharadwaj ML, Singh SP and Sood S. 2016. Genetic diversity for growth and yield traits in bittergourd, International Journal of Vegetable Science. 22(5): 480-489.

Gupta N, Bhardwaj M and Singh S. 2013. Genetic variability and correlation studies in bitter gourd under mid hill conditions of Himachal Pradesh, National Symposium on Abiotic and 
Biotic Stress Management in Vegetable Crops, 39-41.

Iqbal M, Munawar M, Najeebullah M and Din A. 2016. Assessment of genetic diversity in bittergourd, International Journal of Vegetable Science, 22(6): 578-584.

Islam MR, Hossain MS, Bhuiyan MSR, Husna A and Syed MA. 2009. Genetic variability and path coefficient analysis in bitter gourd (Momordica charantia L.), International Journal of sustainable Agriculture, 1(3): 53-57.

Khan MH, Bhuiyan SR, Saha KC, Bhutin MR and Ali ASMY. 2015. Variability, correlation and path coefficient analysis of bittergourd (Momordica charantia L.), Bangladesh Journal of Agriculture Research, 40(4): 607-618.

Kumari M, Behera TK, Munshi AD and Talukdar A. 2015. Inheritance of fruit traits and generation mean analysis for estimation of horticultural traits in bittergourd, Indian Journal of Horticulture, 72(1): 43-48.

Kundu BC, Hossain MA, Main K and Main IH. 2016. Genetic divergence in bittergourd (Momordica charantia L.), Journal of Asiatic society of Bangladesh Science, 38(2): 125-134.

Kutty MS and Dharmatti PR. 2004. Genetic divergene in bittergourd, Karnataka Journal of Agriculture Science, 18(3): 740-743.

Mangal JL, Dixit J, Pandita ML and Sindhu AS. 1983. Genetic variability and correlation studies in bittergourd (Momordica charantia L.), Indian Journal of Horticulture, 40(3): 94-99.

Moharana DP, Shyamal MM, Singh AK and Gautam KK. 2018. Elucidation of correlation and path analysis for various morphological attributes in elite genotypes of bitter melon (Momordica charantia L.), Vegetable science, 45(2):180-184.
Murty BR and Arunachalam V. 1966. The nature of genetic divergence in relation to breeding system in crop plants, Indian journal of genetics, 26A:188-198.

Nandkumar, AA. 2014. Genetic studies in $\mathrm{F}_{3}$ and $\mathrm{F}_{4}$ generations of bitter gourd (Momordica charantia L.),Thesis Abstract: MPKV, Rahuri.

Narayan R, Ahmed N and Mufti S. 2006. Evaluation of some bittergourd genotypes for yield traits and genetic parameters under Kashmir conditions, Environment and Ecology, 24(3A): 750752.

Pathak M, Manpreet and Pahwa K. 2014. Genetic variability, correlation and path coefficient analysis in bittergourd (Momordica charantia $\quad$ L.), International Journal of Advanced Research, 2(8): 179-184.

Praveena VS. 2010. Genetic variability for yield and fruit fly resistance in bittergourd (Momordica charantia L.), Thesis abstract: KAU, Thrissur.

Rajput, LV. 2012. Assessment of variability studies in $\mathrm{F}_{2}$ and $\mathrm{F}_{3}$ generations of bitter gourd (Momordica charantia L.), Ph. D. Thesis, submitted to Mahatma Phule Krishi Vidyapeeth, Rahuri, M.S., India.

Ram D, Rai M, Singh HK, Verma A, Pandey S and Kumar A. 2006. Cause and effect analysis of yield in off-season bittergourd, Vegetable Science, 33(1): 63.

Raman A and Lau C.1996. Anti-diabetic and phytochemistry of Momordica charantia L., Phytomedicine, 2(4): 349362.

Rani KR, Raju CS and Reddy KR. 2015. Variability, correlation and path analysis studies in bitter gourd (Momordica charantia L.), Agricultural Science Digest, 35(2): 106-110.

Rani KR, Reddy KR, Raju CS and Bhave MHV. 2013. Genetic architecture of yield and yield attributing traits of bitter 
gourd, Electronic Journal of Plant breeding, 4(2): 1142-1147.

Rani KR. 2014. Performance of bittergourd genotypes for yield and earliness, Annals of Plant and Soil Research, 16(4): 330-333.

Robinson HF. 1966. Quantitative genetics in relation to breeding on centennial of Mendelium, Indian Journal of Genetics and Plant breeding, 26: 171-187.

Sidhu GK, Pathak M and Chawla N. 2017. Evaluation of bitter gourd (Momordica charantia L.) genotypes for quality traits, Vegetable Science, 44(1): 75-80.

Singh B, Pandey VP and Kumar S. 2012. Genetic variability, correlation and pathcoefficient analysis in bittergourd (Momordica charantia L.), New Agriculturist, 23(2): 239-244.

Singh MK, Bhardwaj DR and Upadhyay DK. 2014. Genetic architecture and association analysis in bittergourd (Momordica charantia L.), The Bioscan, 9(2):707-711.

Singh SP, Kumar S and Singh SP. 2008. Genetic variability, correlation studies and path analysis in bittergourd (Momordica charantia L.), New Agriculturist, 19(1): 105-111.

Singh V, Rana DK and Saha KN. 2017. Genetic variability, heritability and genetic advance in some strains of bitter gourd (Momordica charantia L.) under subtropical conditions of Garhwal Himalaya, Plant Archives, 17 (1):564568.

Talukder ZH, Khan MMH, Das AK, Uddin MN. 2018. Assessment of genetic variability, heritability and genetic advance in bitter gourd (Momordica charantia L.) for yield and yield contributing traits in Bangladesh, Scholar journal of applied sciences and research, 1: 6.

Yadagiri J, Gupta NK, Prabhakar V, Sagar SL and Gurjar PKS. 2016. Genetic variability, heritability and genetic advance for yield and its components of bittergourd (Momordica charantia L.), Green Farming, 7(5): 1077-1079.

Yadav M, Pandey TK, Singh DB and Singh GK. 2013. Genetic variability, correlation coefficient and path analysis in bittergourd, Indian Journal of Horticulture, 70(1): 144-149.

Yadav M, Singh DB, Chaudary R and Singh D. 2008. Genetic variability in bitter gourd (Momordica charantia L.), Indian journal of Horticulture, 65(4): 500-502.

\section{How to cite this article:}

Priyambada Pradhan, Shyama Sourabh and Soumya Sakti Dash. 2020. Genetic Variability, Heritability and Genetic Advance in Bitter Gourd: A Review. Int.J.Curr.Microbiol.App.Sci. 9(07): 3309-3314. doi: https://doi.org/10.20546/ijcmas.2020.907.386 